\title{
THE ANALYSIS OF ENGLISH EDUATION ABSTRACT AT THE ISLAMIC INSTITUTE OF BENGKULU ON THE CONTENT, ORGANISATION AND LANGUAGE
}

\author{
Endang Haryanto \\ State Islamic Institute of Bengkulu \\ Endang.haryanto@yahoo.co.id
}

\begin{abstract}
Theses and journals are several kinds of writing which contain abstract. Thesis is used in educational area, especially in university, as a requirement in completing an academic degree. As one of the most important thesis part is called abstract. The use of abstract is essential in some scientific works, online research, directory, seminar, and call paper. In IAIN Bengkulu, students are obliged to write an abstract as an integral part of their theses. Because of its importance, abstract must be written using the correct form and following the rule of abstracting. This study used descriptive qualitative research. It describes how the students write an abstract based on the rule. As a result, the researcher found some errors on the students' abstract in terms of organization, content, and language. In addition, the researcher found many grammatical errors. Students also tended to make mistake related to the standard form of abstract. Thus, the researcher knows that most of students' abstracts still do not follow the rule of composing their abstract.
\end{abstract}

Keywords: abstract, organization, language

\section{Background}

Writing is a way to communicate with the readers. It is very important in academic level, in as much as the students' works are mostly in the writing form. In this level, this writing is called academic writing. There are many kinds of academic writing that are done by university students, such as write reports, research, dissertation, essay, thesis, etc. in this level writing a thesis is the major points of this study. A thesis is written by university students in order to fulfill the requirement of the degree of strata one in English Department of State Islamic Institute of Bengkulu.

By knowing the entire parts well the thesis can be constructed in the good order and form. Body of thesis is sometimes become the main attention in making the thesis, this part are contained all of the result of the research that was done by the writers. In making the body also needs much time in editing and revising to find the good result of the research finding. 
Although, this part is the major priority of the thesis content, but also there is also the important part of the thesis that is abstract of the thesis. Writing a thesis abstract is a trying, difficult job. After finishing all the hard work of writing all the thesis content, the last thing that is going to do is to write a poor abstract. The thesis abstract is one of the most important sections of the thesis, it can be a big factor in influencing the reader to go to ahead and read the whole thesis and deciding the importance and quality.

The thesis abstract is different from the other abstract that is written on the journal articles or conferences papers. The abstract can be written as one large paragraph. But, commonly at English department of State Islamic Institute is written more than one paragraph. The Writing Support Centre University of Western Ontorio (1998) states Abstracts of research articles are usually one well-developed paragraph, although some cases require multiple paragraphs. It used to make easy the reader to understand each section of the content. Therefore, the abstract content should be covered by these several points, such as: paragraph 1 should be contained the aim and the scope, paragraph 2 a description of the methodology, paragraph 3 a summary of the result, and paragraph 4 the final statement or conclusion. However, it can make the reader really understand the thesis just by reading the abstract.

On the other hand, writing an abstract also need the right organization in order to make systematically process of the writing. Moreover, it is also should be written into the good language, includes the grammar, spelling, formatting, etc. Hence, by doing the writing process in the right form it will be given the good view to the reader. Eventually, this will lead the readers to decide whether or not the writing interests them.

Based on the points above the researcher wants to do further studies about abstract thesis write by the students of English Department of State Islamic Institue of , including each; content, organization and language. Then, the research problems elaborate in three focus of the study; 1) how far do the contents of the abstracts of the English department students of State Islamic Institute of Bengkulu follow the rule of abstracting, 2) how do the English department students of State Islamic Institute of Bengkulu organize their thesis abstract, and 3) what are the errors of language making by the English department students of State Islamic Institute of Bengkulu in writing their thesis abstract.

\section{Review of Related Literature}




\section{A. Writing Thesis}

According to Borg \& Gall (1988:861), there are there major points in the organization of a thesis. Firstly, preliminary, secondly, body of the report (introduction, review of related literature, method, finding, and summary and suggestion); and thirdly, references material. In addition, Emilia, (2009:96) stated the general component of the thesis, such as: Title page, Declaration page, Approval page, Abstract, Acknowledgement, Table of Content, List of figure, Dedication page, Chapter one (Introduction), Chapter two (Review of the literature), Chapter three (Methodology), Chapter four (Result or Findings), Chapter five (Conclusion), Bibliography and References, and Appendices.

\section{B. Abstract}

A paper from Abstract Writing Workshop (2002) defines an abstract as a concise summary of a larger documents, thesis, essay, book, research report, journal publication, etc. that highlights major points covered in the work; concisely describes the content and of the writing; identifies the methodology used; and identifies the findings, conclusions, or intended results. Then, Pearce (2005:51) as quoted by Emilia (2009:119) in her book, states abstract is not only the means by which the thesis will make itself known to the world; it is the set of expectations by which it will be judge.

\section{Content}

According Gengshen \& Yungzhen (2005) an abstract content should show at least four linguistic features: 1) limited length, 2) particular category, 3) complete content, 4) formalized structure. These features are necessarily present in the abstract of articles on hard sciences.

\section{Organization}

The organization in this part is related to the structure of writing the abstract. Hyland (2000) as quoted by Emilia (2009:120) classify the rhetorical move of general structure of the abstract that present on this table: 


\begin{tabular}{ll}
\hline Move & Function \\
\hline Introduction & Establishes context of paper and motivates \\
the research or discussion. \\
Purpose \\
Indicates purposes, thesis or hypothesis, \\
outlines and intention behind the paper. \\
Provides information on design, procedures, \\
assumptions, approach, data, etc. \\
States main findings or results, the \\
argument, or what was accomplished. \\
Interpret or extends results beyond scope of \\
paper, draws inferences, points to \\
applications or wider applications
\end{tabular}

\section{E. Language}

Yano (1999:29) mentioned language is used for expression, verbal thinking, problemsolving, and creative writing. Successful language use for communication presupposes the development of communicative competence in the users of that language and that that use of the language.

\section{Research Design}

Based on the objective of the study the method that used is descriptive qualitative research. It describes how the student write the abstract based on the rule of writing the abstract including the content, organization, and the language. Here, the researcher should collect and arrange some theories in analyzing this work. Related to science, the research design is one of the instrument methods for analyzing in doing something creatively and expressively.

The research design of this study is based on the objective of the study. The objective of the study is describing the phenomenon of how the student of English Department follow the rule in writing the abstract based on the content, organization and language. Based on the objective, this study is designed in a qualitative descriptive approach. It is descriptive since its aim is to provide an accurate description of how to write the good abstract. 


\section{Human as Instrument}

The researcher is a key in collecting the data and must be supported by the other thing that is appropriate. The researcher also needed to be the data collection instrument. He or she must decide what the important thing is and what data are to be recorded that needed in the researcher's study. The researcher also must the recording about what the important information that appropriate with the research.

\section{Notes}

Notes is important notes which gotten by the researcher when collecting the data. A note is list of important information that was found, so the researcher list of information related to the materials that is the abstract of the student of English Education.

\section{Corpuses}

Corpuses is related to the classifying the analysis in every abstract that is use as the sample. It means in every abstract that must be classified based on the organization, grammar, vocabulary, cohesion, coherence, unity, and the mechanical typing. By doing the corpuses, the researcher hopes that the reader can understand easily.

\section{Transcription Guide}

Transcription guide is the good transcription of the abstract that has classified based on the rule of abstracting. It means that the abstract have to categorize based on the classification. Transcription guide also can called recorded transcription which gotten from recorded data from its sources and transcribed recorded data to be a good transcription.

In collecting the accurate data, the following steps were taken:

1. Collecting the data of the student of the best 1 and 2 , since five times graduation.

2. Copy the abstract

3. Classify the organization of the abstract. Coding, such as: organization, grammar, vocabulary, cohesion, coherence, and unity mechanical typing technique.

Along with the data collection, the data were then analyzed using the theories of the rule abstracting. Jacobs (2002: 426) state that the first step in analyzing qualitative data involves organizing the data. Bogdan (1998) suggest that the researcher can actually begin some data analysis in the field, while collecting the data. The researcher assumes that the data 
is the important things to support the researcher's research in this thesis. The following steps of analyzing the data collections are:

1. Analyzing the organization of the abstract whether each abstract follows the rule of organizing abstract.

2. Analyzing the grammar error whether each abstract has correct grammar.

3. Analyzing the vocabulary whether each abstract use the appropriate vocabulary.

4. Analyzing the cohesion, coherence, and unity of each parts of the abstract.

5. Analyzing the mechanical typing technique of the abstract whether each abstract follow the rule of typing an abstract or not.

\section{Results}

\section{Organization}

The researcher showed the number of error belonging to the organization of the abstract. The classification of the error is categorized based on the arrangement of the paragraph showed in the abstract. In this case, the organization of the abstract mostly doesn't discuss the component of the thesis of each chapter of the thesis. Here, based on the sample of students abstract, there was found that the students only represent the component of chapter 1 , chapter 3 , chapter 4 and chapter 5 . It means that the students only describe the introduction, research methodology, finding, conclusion and discussion.

The data also showed only one abstract put down the chapter two on the abstract. However, the researcher found the composition of each paragraphs were not effective enough, the arrangement of each paragraph was not on the right order. Example (in Abstract 8)

Paragraph 3: The objective of the study is to know the effectiveness of group work activity in helping the students to increase their speaking ability.

Paragraph 4: Review of related literature is about the definition of speaking, some element that influence students' speaking ability, the objective of speaking, some problem in teaching speaking, and the previous research finding including the hypothesis of the study.

The data showed that the paragraph is not effective, because the sentence is to limited, the only one sentences on that paragraph. Because, a good paragraph they have to have topic 
sentence, supporting sentence and supporting details. So, for these paragraphs it is supposed to be combined with the other paragraph that is correlated with other paragraph.

\section{Grammar}

Many kinds of errors found which are made by the students in composing their abstract, especially in the grammar. In this case, the number of errors tends to make the abstract monotone and not effective in the composition. So, these following examples will show the number of errors that found in the students abstract, such as:

\section{Example (in abstract 8, paragraph 4)}

Review of related literature is about the definition of speaking, some element that influence students' speaking ability, the objective of speaking, some problem in teaching speaking, and the previous research finding including the hypothesis of the study.

\section{It is supposed to be:}

Review of related literature is about the definition of speaking, some elements that influence students' speaking ability, the objective of speaking, some problems in teaching speaking, and the previous research finding includes the hypothesis of the study.

This error is concerning the incorrect use of plural and singular. In this example showed that the missing (-s) for the plural noun frequently happens. The word problem in the sentence above should be added (-s) become problems.

\section{Vocabulary}

The data showed the students are used right diction in every word of the sentences in their abstract. From the ten samples only five students are made the error in the diction of vocabulary. Furthermore, the number of errors in vocabulary is not as much as the errors in grammar. Here, the example of error in vocabulary as follows:

(In abstract 3): The word mark it is supposed to be score

(In abstract 8): The word class it is supposed to be grade

Based on the example above, the error is frequently happens because the students forgot the difference function of word which is chosen. The function of word mark is to show the quality of work done at school, in this case the students exercise, task and examination, but not to show the number of point that the students get. So, the word mark is supposed to be changed 
by score. Because, this word is directly aimed at the number of point that students get in their work. The word class also wrong, because this word aimed at whole number of students. So, it is supposed to be changed by grade, because it makes specification.

\section{Coherence}

Coherence in this analysis is aimed to know the connection of each paragraph of the abstract, and it is to know the function of the transition signal of each paragraph. The data finding showed that there is no error in the used of transition signal of the paragraph on these abstract. The students used the transition signal creatively, so it makes the reader easy to understand the content of the abstract.

\section{Unity}

This part of analysis is to know the unity of each sentence in the paragraph whether each sentences really support the main idea or not. The data showed that some paragraphs of the students' abstracts are not unity. The supporting sentence of the paragraph is not clearly support the main idea of the paragraph. So, it makes the paragraph monotone and not interested. Because, there are still many repetitions of the explanation but actually the purpose is the same point. For example:

"English can be learned by every student easily, learner can learn it by using many ways. In other hand the teacher must have special method in teaching English and it becomes big duty for the teacher. Teaching English to elementary students is quite difficult because the student tend to play relax. The teacher is expected to capable leading the students to recognize English early because it is the first time for the students to know English. In addition English becomes an international language and of course in this globalization era, the students have to struggle to get standard of competence and they must compete with others to get better future."

In this example, the researcher found that this paragraph is not unity. The supporting sentences in this paragraph are not clearly support the main idea. In the first sentence, the writer has been expressing the general point of the introduction of the background of the study. It was about the difficulties to use the method in teaching at elementary. The writer also has been choosing the sentence to support the main idea of this paragraph. Here, the ambiguity happened when the writer wrote the last sentence about the English as an international language. In this 
case, the writer suggested to explain it in the first sentence of paragraph or omitted that sentence. It will make that paragraph effective and efficient.

\section{Discussion}

Based on the data that analyzed by using the standard rule of abstract, there are some characteristics of error that are founded in the students abstract. In the students abstract are founded that most of students abstract have errors, such as; 1) Organization Error, 2) Grammar Error, 3) Vocabulary Error, 4) Coherence, 5) unity. After gaining the analysis results from all previous data analysis, the researcher concluded the final result into the several points based on those five characteristic of errors above:

The first point showed that the composition of the organization of the students abstract still does not follow the rule of abstracting. The number of word is still more than 300 words. And then each paragraph does not discuss the component of each chapter of the thesis. Some samples found that in composing the paragraph the students still not effective and efficient. The researcher found some paragraphs only consist of one sentence.

The second point showed the highest error is in the grammatical error. The grammatical error is classified into the Error in the Content of Word (Part of speech, such as: verb, noun, adjective and adverb), Error in Function of Words (preposition and conjunction), and Error in the Mechanics (period, comma, semicolon, and capital word).

The next point is the error in choosing the diction on the vocabulary. Here, from some samples showed that the students still choose the general word to explain some terms that use in educational area.

The fourth point showed that the effectiveness of using the transition signal. The transition signal is used creatively, so it makes the reader easy to understand the content of the abstract.

The last point is about the unity in the paragraph. The data finding show in each paragraph of students abstract there are still found paragraph that are ambiguous. The supporting sentence in the paragraph sometime does not the main point of the paragraph.

From the total of abstract being analysis, the researcher know that most of abstract still do not follow the rule in composing the good abstract based on the standardization. Students 
must also understand how to compose the good abstract. As a recommendation, students can also learn these theories: The rule of abstracting (organization, content, and language), Content of word (Part of Speech), function word, paragraph structure. Hopefully, with the above suggestions, students will be able to write a correct abstract and in overall, a correct thesis.

\section{Conclusion}

Actually, this study has a relationship with academic writing; consequently the researcher wants to learn about the academic writing, especially writing abstract and whole parts includes in these There are three conclusions that are presented here and the answer the objective of the study: to know how far the organization, content, and language of the students abstract follow the rule of abstracting, it is reflected by using the standard form of writing the abstract.

The researcher uses the method based on the standard form of writing the abstract in this university and the general rule from the several experts. The researcher takes the result that whole abstracts have the errors in the organization, content and language.

First, the organization form found in the students' abstract. In organization of the abstract, the student still not effective to organized their abstract. Here, in the abstract the students still use too many words, and the paragraph also is not organized well. In other word, the student cannot be composed the abstract as short as possible.

Second, the content of the abstract include the component inside the paragraph of the abstract. In this case, the abstract content is not representing the component of each chapter of the thesis. Furthermore, for some abstracts the unity of the paragraph is not related each other, they cannot support the main idea of paragraph well. But then, each paragraph is coherence to another. The students are good enough in using the transition signal to connect the sentences well, so it can make the reader easy to understand the content of the abstract.

The last is language used inside of the abstract. Language in this study is related to the grammatical process of sentence found in each paragraph. In analyzing, the researcher found many errors made by the students in composing the abstract. Grammatical error in this study is classified into the Error in the Content of Word (Part of speech, such as: verb, noun, adjective and adverb), Error in Function of Words (preposition and conjunction), and Error in the Mechanics (period, comma, semicolon, and capital word). 
From those three conclusions, it is found that is composing the abstract the students make many mistake almost in the organization, content and language. So, it can be concluded that the abstract that are made by the students do not follow the rule of abstracting, based on the organization, content and language.

\section{REFERENCES}

Emilia, Emi. (2008). Menulis Tesis dan Disertasi. Bandung: Alfabeta

Gengshen, Hu \& Shen Yunzhen. Professional Paper Writing and Publication: Abstract. n.d. 27 october $2005 .<$ no URL $>$

Hyland, K. (2000b). Academic Hedging and Students Writing. Canbridge: Canbridge University Press.

Oshima, A \& Hogue, A. (1999). Writing Academic English. (Third Edition). Addison Wesley: Longman.

Paltridge, B \& Satrfield, S. (2007). Thesis and Dissertation Writing in a Second Language. London: Routledge.

http://The Journal_Article_Abstract.pdf, accessed on March, 292011.

http://Academic Task_Abstract_Writing/Presentation.pdf, accessed on March, 292011.

http://en.wikipedia.org/wiki/Language, accessed on December, 272010.

www.yourdictionary.com, accessed on January, 52011. 